\title{
Effect of an innovative community based health program on maternal health service utilization in north and south central Ethiopia: a community based cross sectional study
}

Mesganaw Fantahun Afework ${ }^{1 *}$, Kesteberhan Admassu $^{2}$, Alemayehu Mekonnen $^{1}$, Seifu Hagos ${ }^{1}$, Meselech Asegid ${ }^{1}$ and Saifuddin Ahmed $^{3}$

\begin{abstract}
Background: Among Millennium Development Goals, achieving the fifth goal (MDG-5) of reducing maternal mortality poses the greatest challenge in Sub-Saharan Africa. Ethiopia has one of the highest maternal mortality ratios in the world with unacceptably low maternal health service utilization. The Government of Ethiopia introduced an innovative community-based intervention as a national strategy under the Health Sector Development Program. This new approach, known as the Health Extension Program, aims to improve access to and equity in essential health services through community based Health Extension Workers.
\end{abstract}

Objective: The objective of the study is to assess the role of Health Extension Workers in improving women's utilization of antenatal care, delivery at health facility and postnatal care services.

Methods: A cross sectional household survey was conducted in early 2012 in two districts of northern and south central parts of Ethiopia. Data were collected from 4949 women who had delivered in the two years preceding the survey. Logistic regression analysis was performed to determine the association between visit by Health Extension Workers during pregnancy and use of maternal health services, controlling for the effect of other confounding factors.

Results: The non-adjusted analysis showed that antenatal care attendance at least four times during pregnancy was significantly associated with visit by Health Extension Workers [Odds Ratio 3.46(95\% Cl 3.07,3.91)], whereas health facility delivery (skilled attendance at birth) was not significantly associated with visit by Health Extension Workers during pregnancy [Odds Ratio 0.87(95\% Cl 0.25,2.96)]. When adjusted for other factors the association of HEWs visit during pregnancy was weaker for antenatal care attendance [Adjusted Odds Ratio: 1.35(95\% Cl: 1.05, 1.72)] but positively and significantly associated with health facility delivery [Adjusted Odds Ratio 1.96(1.25,3.06)].

Conclusion: In general HEWs visit during pregnancy improved utilization of maternal health services. Health facility delivery is heavily affected by other factors. Meaningful improvement in skilled attendance at birth (health facility delivery) should include addressing other factors on top of visits by HEWs during pregnancy and specific target oriented interventions during visits by HEWs to support skilled attendance at birth.

Keywords: Skilled attendance at birth, Community based health programs, Health facility delivery, Antenatal care, Health Extension Worker, Ethiopia

\footnotetext{
* Correspondence: mesganaw.@@gmail.com

'Department of Reproductive Health and Health Service Management,

School of Public Health, College of Health Sciences, Addis Ababa University,

Addis Ababa, Ethiopia

Full list of author information is available at the end of the article
} 


\section{Background}

Among Millennium Development Goals (MDGs), achieving the goal for MDG5 (Maternal Health Goal), poses the greatest challenge in Sub-Saharan Africa [1-3]. Ethiopia has one of the highest maternal mortality ratios in the world [2-4] and maternal health service utilization in Ethiopia is low. The 2011 Ethiopian Demographic and Health Survey (EDHS 2011) reported that $34 \%$ of women used antenatal care (ANC), 10\% women delivered with skilled attendance at birth $(\mathrm{SAB})$ and $9 \%$ received postnatal care with regional variations [4].

To ameliorate this unacceptably low maternal care utilization, the Government of Ethiopia introduced an innovative community-based intervention as a part of the Health Sector Development Program II. The main aim of this new approach, known as the Health Extension Program (HEP), is to improve access to and equity in essential health care through community based outreach health services at the doorsteps of the residents [5-7]. The HEP was started in 2003 and services are provided by a new cadre of female health workers, known as Health Extension Workers (HEWs). Currently, more than 35000 HEWs are working in the country. Two HEWs are deployed in each kebele. Kebele is the smallest administrative unit in Ethiopia. HEWs are full time employees of national health system, and are trained for one year after completing grade 10 of school. They are considered as the first point of contact of the community with the health system, delivering integrated preventive, promotive and curative health services, with a special focus on maternal and child health [6]. While they may provide basic ANC and may conduct home delivery, they may not be adequately trained in midwifery skills to proficiency.

Previous studies showed that the health extension program has contributed in improving contraceptive use [8] and utilization of some components of maternal health services. However, the evidence on improving skilled attendance at birth or health facility delivery by HEW visits is still limited. Two studies conducted between 2008-2010 $[9,10]$ found no association of HEW visits with SAB, which is considered a key process indicator for MDG 5 . These studies also reported poor knowledge of HEWs on maternal complications and maternal counseling.

The Health Sector Development Program IV (HSDP IV 2010/11-2014/15) set new and higher targets to increase deliveries attended by skilled attendants from $18 \%$ to $60 \%$, and to decrease the maternal mortality ratio from 590 per 100,000 live births to 267 per 100000 livebirths [5]. Subsequently, several actions were taken to improve knowledge and skills of HEWs including the integrated refresher training of HEWs $[11,12]$. The current study will therefore provide information on the effects of HEWs visit on maternal care utilization in recent period.

\section{Methods}

A community based cross sectional study was conducted in two of the nine administrative regions of the EthiopiaTigray in the north; and the Southern Nations, Nationalities, and People's Region (SNNPR) in the south. These study areas were selected purposefully. These two regions are home to a university that is currently being mentored by Addis Ababa University (AAU) and run a health and demographic surveillance system (HDSS) in the selected for the study districts. Maternal health service utilization indicators in the selected regions indicate Tigray has ANC at least once levels of $65 \%$, SAB (11.6\%), and post natal visits in the first 2 days. SNNPR had ANC at least once rate of $41 \%, \mathrm{SAB}(6.2 \%)$, and postnatal visit in the first 2 days $(5.5 \%)$ [4].

We selected 12 kebeles from the two districts namely Wukro in northern Ethiopia and Butajira in south central Ethiopia. Six kebeles each were selected using simple random sampling procedure from HDSS sites and non-HDSS sites in each district to control the effect exposure to health and demographic surveillance activities. These 12 Kebeles were selected proportionally from urban and rural areas, 2 from urban kebeles and 10 from rural kebeles.

The study population included all women 15-49 of age, married or unmarried, who delivered within last two years in the selected kebeles, irrespective of the status of birth outcome whether live birth or stillbirth.

The Ethiopian Crude Birth Rate (CBR) was estimated at 34.5/1000 midyear population [4]. With this CBR on an average we expected to have about 104 births per year in a kebele with an approximate population size of 3000. In 12 kebeles in each of the two districts, about 2496 deliveries were expected per site during 2 years of retrospective observation period. Thus, we expected about 4992 women as the target population in these study areas for this and other studies which assessed differentials in health service utilization by different determinants.

Of the 4981 women approached for the interview 14 women were not available for interview after repeat visits and 18 questionnaires were discarded because of inconsistencies. A total of 4949 (99, 3\%) women were finally included in the study.

Home visit by a HEW at least once during pregnancy was taken as the independent variable of interest and ANC visit at least four times and skilled attendance at birth (health facility delivery) as the dependent variable.

Initial sample size calculations for this and other studies on maternal health service utilization were based on $\mathrm{SAB}$ rate of $16 \%$ around the time of the survey [8]. With the sample of women included in the study a difference of $4 \%$ would be detected between those who were visited by HEWs at least once and those not visited with a power of $80 \%$ and a maximum design effect of 2 . Ethical approval for this study was obtained from the Institutional 
Review Board Office, John Hopkins Bloomberg School of Public Health and Institutional Review Board of the College of Health Sciences, Addis Ababa University.

\section{Data collection}

Data collection was conducted by twenty trained and experienced female interviewers, who were high school graduates using questionnaire that contained socio-demographic characters tics of the respondents, visit by HEWs during pregnancy and use of maternal health services. Data collection activities were monitored by two supervisors in each study district. The supervisors had a minimum of a bachelor degree education and previous experience in supervising community based data collection.

A sampling list of household members was constructed through a census of households and eligible women who had delivered during the previous two years were identified. All eligible women who voluntarily consented participated in the study after listening to the interviewer reading the informed consent. Supervisors randomly interviewed about $4 \%$ of the women for checking the reliability of responses as a part of data quality monitoring. A pretest was conducted in a district not selected for the study and some revisions were made on the questionnaire to improve clarity and understandability by the respondents.

\section{Data entry and analysis}

Data were double entered in a customized data entry program by experienced data clerks. Data analysis was performed using STATA 12 (Stata Corp, Texas). Data quality was checked by examining missing responses, inappropriate values, and violation of skip rules.

A wealth index score was constructed for each household with a principal component analysis of household durable goods, household structure conditions (eg, materials used to construct wall, roof, floor of houses, type of toilets), and land possessions. Households were ranked according to the total wealth score and then divided into wealth quintiles as a proxy of household socio-economic status.

We examined the distribution of socio-demographic characteristics of the study population, the coverage of maternal health services and association between visit by HEWs and other factors with use of maternal health services (Antenatal Care at least four times, Institutional Delivery including health posts, health centers and hospitals and Postnatal Care within three days). Multi collinearity was checked by calculating variance inflation factor (VIF) and we applied complex survey data analysis specifying survey design and sampling unit (kebeles). The variance was adjusted with Taylor linearized variance estimation method. Multivariate logistic regression analysis adjusted for cluster level sampling (kebele) was then run to control for the effect of other factors for which literature review showed association with maternal health service utilization (Eg 13.). Odds ratios (95\% confidence intervals) were calculated to determine the association between antenatal care attendance at least four times, institutional delivery, postnatal care within three days of delivery and predictor variables.

\section{Results}

Visit of HEWs at least once by socio-demographic characteristic of the study population is shown in Table 1. About $65 \%$ of the women in rural areas and 53\% in urban areas answered that they were visited by HEWs during pregnancy of the index child. Two thousand forty six (67\%) of those who were unable to read and write were visited by HEWs, whereas it was about $38 \%$ of those who had college education that were visited by HEWs. HEW's visit during pregnancy was reportedly lower for Muslims and Protestants (28\% each) compared by Orthodox Christians. About $90 \%$ and $36 \%$ of the housewives and the traders or employees respectively answered that they were visited by HEWs during pregnancy of the index child.

Table 2 shows the maternal health service utilization status of women who delivered in the previous two years. Four thousand four hundred eight (89.1\%) women reported that they had attended ANC at least once, whereas $57.6 \%$ had attended ANC at least four times during the pregnancy of the index child. About $29 \%$ of the women started to attend ANC during the first trimester whereas 68.3\% started attending ANC during the second trimester. Regarding place of delivery, three-fourth of the women delivered the index child at home, followed by delivery in government hospitals (16.1\%) and health centers (7.8\%). About $88 \%$ said that they had visited a health facility for post natal care. Of these $3.7 \%$ visited a health facility within 24 hours and $10.2 \%$ within 3 days after delivery.

Table 3 shows the association of visit by HEWs during pregnancy and other factors with ANC attendance at least four times. The odds of attending ANC at least 4 times by those who were visited during pregnancy at least once was about 3 times higher than those who were not visited by HEWs, adjusted for other factors. Rural residents had about $60 \%$ chance of attending ANC at least four times compared to urban residents. Other factors that showed significant association with attendance at least four times during pregnancy include wealth quintile and number of pregnancies.

Visit by HEWs was not significantly associated with institutional delivery in crude analysis. Adjusted for other factors the odds of delivering the index child in health facility was about twice among those who were visited by HEWs compared with those who were not. Mother's age, educational status, place of residence, wealth quintile and number of pregnancies were also significantly associated with place of delivery in multivariate analysis (Table 4).

On the other hand those who were visited by HEWs during pregnancy were highly likely to attend post natal 
Table 1 Socio-demographic characteristics of women who delivered a baby in the two years preceding the survey by HEWs visit during pregnancy in north and south central Ethiopia, 2012

\begin{tabular}{|c|c|c|}
\hline \multirow[b]{2}{*}{ Characteristics } & \multicolumn{2}{|c|}{$\begin{array}{l}\text { Visit by HEWs during } \\
\text { pregnancy at least once }\end{array}$} \\
\hline & Yes $(n, \%)$ & No $(n, \%)$ \\
\hline \multicolumn{3}{|l|}{ Place of residence } \\
\hline Urban & $620(53.0)$ & $550(47.0)$ \\
\hline Rural & $2465(65.2)$ & 1314(34.8) \\
\hline \multicolumn{3}{|l|}{ Level of education } \\
\hline None & $2046(66.0)$ & 1052(34.0) \\
\hline Primary & $757(55.5)$ & $608(44.5)$ \\
\hline Secondary & $252(62.7)$ & 150(37.3) \\
\hline College & $30(35.7)$ & $54(64.3)$ \\
\hline \multicolumn{3}{|l|}{ Marital status } \\
\hline Currently married & $2921(62.1)$ & 1785(37.9) \\
\hline Widowed, divorced, never married & $164(67.5)$ & $79(32.5)$ \\
\hline \multicolumn{3}{|l|}{ Religion } \\
\hline Orthodox Christian & $2602(79.3)$ & $679(20.7)$ \\
\hline Muslim & $379(26.8)$ & 1033(73.2) \\
\hline Protestant & $529(26.8)$ & $142(63.2)$ \\
\hline Catholic & $49(83.1)$ & 10(17.0) \\
\hline \multicolumn{3}{|l|}{ Occupation } \\
\hline Housewife & 1754(89.9) & 197(10.1) \\
\hline Housewife and farm work & $992(46.8)$ & $1127(53.2)$ \\
\hline Trade and other employee & $217(36.4)$ & $379(63.6)$ \\
\hline Others & $122(43.1)$ & 161(56.9) \\
\hline \multicolumn{3}{|l|}{ Number of pregnancies } \\
\hline 1 & $522(54.4)$ & 437(45.6) \\
\hline $2-4$ & $1390(62.6)$ & 832(37.4) \\
\hline $5-6$ & $680(62.3)$ & $346(33.7)$ \\
\hline 7 and above & $4939(66.4)$ & 249(33.6) \\
\hline \multicolumn{3}{|l|}{ Number of deliveries } \\
\hline $1-2$ & 1049(59.1) & $726(40.9)$ \\
\hline $3-4$ & $858(61.2)$ & 543(38.8) \\
\hline $5-6$ & $680(62.3)$ & $346(33.7)$ \\
\hline $7+$ & $493(66.4)$ & 249(33.6) \\
\hline
\end{tabular}

care during the first three days [AOR 3.68(2.05,6.59)] while other factors except number of pregnancies did not appear to make a significant difference in postnatal care visit within the first three days after delivery (Table 5).

\section{Discussion}

Visit by HEWs during pregnancy improved ANC utilization. This is expected as one of the main reasons for the HEWs home visit is to encourage women to attend
Table 2 Maternal health services utilization among women who delivered in the two years preceding the survey in north and south central Ethiopia, 2012

\begin{tabular}{lcc}
\hline Maternal health services & Frequency & Percent \\
\hline Had antenatal care at least once & & \\
Yes & 4408 & 89.1 \\
No & 541 & 10.9 \\
Time at first ANC visit & & \\
First trimester & 1255 & 28.5 \\
Second trimester & 3003 & 68.3 \\
Third trimester & 144 & 32.7 \\
N $=4402$ & &
\end{tabular}

Had antenatal care at least four times

$\begin{array}{lcc}\text { Yes } & 2850 & 57.6 \\ \text { No } & 2099 & 42.4 \\ \text { Place of ANC attendance } & & \\ \text { Health post } & 2001 & 45.6 \\ \text { Health center } & 1748 & 39.8 \\ \text { Hospital } & 639 & 14.6\end{array}$

$$
n=4388
$$

\section{Place of delivery}

\begin{tabular}{lcc} 
Home & 3700 & 74.9 \\
Health post & 34 & 0.7 \\
Health center & 386 & 7.8 \\
Government hospital & 793 & 16.1 \\
Private hospital & 24 & 0.5 \\
Had post natal care & & \\
Yes & 4343 & 88.1 \\
No & 589 & 11.9 \\
Time at post natal care visit & & \\
Within 24 hours & 162 & 3.7 \\
Within 3 days & 444 & 10.2 \\
Within 7 days & 2061 & 47.5 \\
45 days after delivery & 886 & 20.4 \\
Later & 483 & 11.1 \\
Unspecified & 307 & 7.1 \\
Place of PNC visit & & \\
Health post & 2500 & 57.9 \\
Health center & 1123 & 26.0 \\
Government hospital & 648 & 15.0 \\
Private clinic & 24 & 0.6 \\
Private hospital & 20 & 0.5 \\
Unspecified & 2 & 0.05 \\
\hline
\end{tabular}

ANC. A study mentioned above [8] reported higher coverage of ANC where visits of HEWs and voluntary community health workers were frequent. 
Table 3 Association of HEWs and other factors with with ANC at least four times in north and south central Ethiopia, 2012

\begin{tabular}{|c|c|c|c|c|}
\hline \multirow[t]{2}{*}{ Characteristics } & \multicolumn{2}{|c|}{ Had ANC four times } & \multirow[t]{2}{*}{ Crude OR $(95 \% \mathrm{Cl})$} & \multirow[t]{2}{*}{ Adjusted OR $(95 \% \mathrm{Cl}$} \\
\hline & YES $(n, \%)$ & NO $(n, \%)$ & & \\
\hline \multicolumn{5}{|c|}{ Visit by HEWs during pregnancy } \\
\hline None & $726(38.9)$ & 1138(61.1) & 1.00 & 1.00 \\
\hline Visisted at least once & $2124(68.8)$ & $961(31.2)$ & $3.46(2.11,5.66)$ & $3.42(2.62,4.47)^{*}$ \\
\hline \multicolumn{5}{|l|}{ Place of residence } \\
\hline Urban & $796(68.0)$ & $374(32.0)$ & 1.0 & 1.00 \\
\hline Rural & $2054(54.4)$ & $1725(45.6)$ & $0.56(0.24,1.29)$ & $0.66(0.49,0.89)^{*}$ \\
\hline \multicolumn{5}{|l|}{ Mothers age (years) } \\
\hline $15-19$ & $126(56.3)$ & $98(43.7)$ & 1.0 & 1.00 \\
\hline $20-29$ & 1474(58.3) & 1053(41.7) & $1.09(.088,1.35)$ & $1.07(0.79,1.46)$ \\
\hline $30-39$ & $1088(57.3)$ & $810(42.7)$ & $1.04(0.77,1.42)$ & $1.19(0.78,1.82)$ \\
\hline $40-49$ & $160(55.0)$ & $131(45.0)$ & $0.95(0.58,1.56)$ & $1.40(0.73,2.69)$ \\
\hline \multicolumn{5}{|l|}{ Women's education } \\
\hline None & $1736(56.1)$ & $1362(43.9)$ & 1.0 & 1.00 \\
\hline Primary & $764(56.0)$ & $601(44.0)$ & $0.99(0.81,1.23)$ & $0.95(0.81,1.12)$ \\
\hline High school & $290(72.1)$ & 112(27.9) & $2.03(1.20,3.43)$ & $1.29(1.06,1.59)^{*}$ \\
\hline College/University & $60(71.4)$ & $24(28.6)$ & $1.96(0.82,4.72)$ & $1.35(0.75,2.42)$ \\
\hline \multicolumn{5}{|l|}{ Marital status } \\
\hline Currently married & $2717(57.7)$ & 1989(42.3) & 1.0 & 1.00 \\
\hline Currently unmarried & $133(54.7)$ & $110(45.3)$ & $0.89(0.62,1.27)$ & $0.72(0.51,1.02)$ \\
\hline \multicolumn{5}{|l|}{ Wealth quintile } \\
\hline Poorest & $718(72.2)$ & $277(27.8)$ & 1.0 & 1.00 \\
\hline Poor & $599(60.3)$ & 395(39.7) & $0.59(0.33,1.03)$ & $0.67(0.42,1.08)$ \\
\hline Middle & $408(41.2)$ & $582(58.8)$ & $0.27(0.16,0.46)$ & $0.43(0.26,0.69)^{*}$ \\
\hline Rich & $456(46.7)$ & $521(53.3)$ & $0.34(0.21,0.54)$ & $0.52(0.33,0.83)^{*}$ \\
\hline Richest & $669(67.4)$ & $324(32.6)$ & $0.79(0.42,1.56)$ & $0.883(0.58,1.34)$ \\
\hline \multicolumn{5}{|l|}{ Number of pregnancies } \\
\hline 1 & $601(62.7)$ & $358(37.3)$ & 1.0 & 1.00 \\
\hline $2-4$ & $1320(59.4)$ & $902(40.6)$ & $0.87(0.67,1.14)$ & $0.84(0.65,1.08)$ \\
\hline $5-6$ & $572(55.8)$ & $454(44.2)$ & $0.75(0.51,1.11)$ & $0.63(0.41,0.97)^{*}$ \\
\hline 7 and above & $357(48.1)$ & $385(51.9)$ & $0.55(0.38,0.81)$ & $0.43(0.30,0.62)^{*}$ \\
\hline
\end{tabular}

${ }^{*} \mathbf{p}<0.05$.

Visit by HEWs during pregnancy was not statistically significantly associated with institutional delivery in crude analysis. However, adjusted for other factors, visit by HEWs during pregnancy had a positive and significant effect on institutional delivery. This may be the result of the overwhelming effect of other factors. Relevant literature shows the mechanism of how different factors affect maternal health services [13]. For example urban residents have better access to health facilities both in number, type and level of care they provide in this and other developing country contexts, which may encourage the use of facility delivery by the residents.

As in the case of ANC at least four times those who were visited by HEWs during pregnancy were highly likely to attend post natal care during the first three days. The reason for the similarity between the influence of .visit by HEWs on ANC and postnatal care attendance, and the difference from health facility delivery may need to be explored further. However, it may be speculated that ANC and postnatal care visits can be planned, where as labor is often unplanned and delivery in health facilities needs preparedness in terms of resources and decision making. This may also explain the observed difference between ANC attendance and skilled attendance at birth (health facility delivery) rates in this and other studies $[4,8]$. Interviews with 19 HEWs in the study area revealed that only 12 of the HEWs informed women about "Birth Preparedness", (Unpublished report from this research) the 
Table 4 Association of HEWs visit during pregnancy and other factors with place of delivery in north and south cetral, Ethiopia 2012

\begin{tabular}{|c|c|c|c|c|}
\hline \multirow[t]{2}{*}{ Characteristics } & \multicolumn{2}{|c|}{ Place of delivery } & \multirow[t]{2}{*}{ Crude OR $(95 \% \mathrm{Cl})$} & \multirow[t]{2}{*}{ Adjusted OR $(95 \% \mathrm{Cl}$} \\
\hline & Health facility $(n, \%)$ & Home $(n, \%)$ & & \\
\hline \multicolumn{5}{|c|}{ Visit by HEWs during pregnancy } \\
\hline None & 497(26.7) & $1367(73.3)$ & 1.00 & 1.00 \\
\hline Visisted at least once & $740(24.0)$ & $2345(76.0)$ & $0.87(0.25,2.96)$ & $1.96(1.25,3.06)^{*}$ \\
\hline \multicolumn{5}{|l|}{ Place of residence } \\
\hline Urban & $704(60.2)$ & $466(39.8)$ & 1.00 & 1.00 \\
\hline Rural & $533(14.1)$ & & $0.11(0.03,0.30)$ & $0.49(0.26,0.90)^{*}$ \\
\hline \multicolumn{5}{|l|}{ Mothers age (years) } \\
\hline $15-19$ & $80(35.7)$ & 144(63.3) & 1.00 & 1.00 \\
\hline $20-29$ & $714(28.3)$ & 1813(71.8) & $0.71(0.55,0.91)$ & $1.25(0.82,1.90)$ \\
\hline $30-39$ & $408(21.5)$ & $1490(78.5)$ & $0.49(0.32,0.76)$ & $2.25(1.32,3.85)^{*}$ \\
\hline $40-49$ & $32(11.0)$ & 259(89.0) & $0.22(0.14,0.35)$ & $2.35(1.27,4.33)^{*}$ \\
\hline \multicolumn{5}{|l|}{ Women's education } \\
\hline None & $440(14.2)$ & 2658(85.8) & 1.00 & 1.00 \\
\hline Primary & 434(31.8) & $931(68.2)$ & $2.81(2.25,3.52)$ & $1.19(0.97,1.46)$ \\
\hline High school & $291(72.4)$ & $111(27.6)$ & $15.84(8.76,28.65)$ & $2.757(1.90,3.99)^{*}$ \\
\hline College/University & $72(85.7)$ & $12(14.3)$ & $36.25(15.40,85.30)$ & $3.943(1,64,9.46)^{*}$ \\
\hline \multicolumn{5}{|l|}{ Marital status } \\
\hline Currently married & $1144(24.3)$ & $3562(75.7)$ & 1.00 & 1.00 \\
\hline Currently unmarried & 93(38.3) & 150(61.7) & $1.93(1.19,3.12)$ & $1.317(0.94,1.84)$ \\
\hline \multicolumn{5}{|l|}{ Wealth quintile } \\
\hline Poorest & 79(7.9) & $916(92.1)$ & 1.00 & 1.00 \\
\hline Poor & $122(12.3)$ & $872(87.3)$ & $1.62(1.09,2.41)$ & $1.61(1.15,2.24)^{*}$ \\
\hline Middle & 85(8.6) & 905(91.4) & $1.09(0.64,1.59)$ & $1.37(0.87,2.15)$ \\
\hline Rich & 231(23.6) & $746(76.4)$ & $3.60(2.10,6.13)$ & $3.73(2.34,5.95)^{*}$ \\
\hline Richest & $720(72.5)$ & $273(27.5)$ & $30.60(15.22,61.43)$ & $16.33(7.59,35.11)^{*}$ \\
\hline \multicolumn{5}{|l|}{ Number of pregnancies } \\
\hline 1 & 474(49.4) & 485(50.6) & 1.00 & 1.00 \\
\hline $2-4$ & $532(23.9)$ & $1690(76.1)$ & $0.32(0.25,0.41)$ & $0.35(0.26,0.46)^{*}$ \\
\hline $5-6$ & 158(15.4) & 868(84.6) & $0.87(0.13,0.26)$ & $0.24(0.16,0.35)^{*}$ \\
\hline 7 and above & 73(9.8) & $669(90.2)$ & $0.11(0.07,0.17)$ & $0.18(0.12,0.26)^{*}$ \\
\hline
\end{tabular}

${ }^{*} p<0.05$.

main component of which is planning and preparing for a skilled attendant at birth. Several studies have documented the importance of birth preparedness in seeking assistance of skilled birth attendants $[14,15]$. An earlier study in Tigray administrative region of Ethiopia reported low rate of birth preparedness [16].

There is an agreement about the relationship of HEWs visit and use of ANC services with studies conducted in Ethiopia earlier $[9,10]$. In a way, the findings of the effect of HEWs visit on health facility delivery (skilled attendance at birth) are also similar with the previous studies because no significant association was observed between visit by
HEWs and health facility delivery in crude analysis. However, adjusted for other factors visit by HEWs during pregnancy was significantly associated with health facility delivery in this study thus revealing the fact that not much improvement can be expected in skilled attendance at birth by the visits of HEWs alone, without attending to the effects of other factors. Policies and strategies to improve skilled attendance at birth should consider these findings into consideration.

Four thousand four hundred eight women (89\%) reported to have attended ANC at least once and 2850 (57\%) at least four times. This is much higher than reported by 
Table 5 Association of HEW's visit during pregancy and other factors with postnatal care service within three days in north and south central Ethiopia, 2012

\begin{tabular}{|c|c|c|c|c|}
\hline \multirow[t]{2}{*}{ Characteristics } & \multicolumn{2}{|c|}{ Postnatal care service within three days } & \multirow[t]{2}{*}{ Crude OR $(95 \% \mathrm{Cl})$} & \multirow[t]{2}{*}{ Adjusted OR $(95 \% \mathrm{Cl}$} \\
\hline & YES $(n, \%)$ & NO $(n, \%)$ & & \\
\hline \multicolumn{5}{|c|}{ Visit by HEWs during pregnancy } \\
\hline None & $91(4.9)$ & 1173(95.1) & 1.0 & 1.0 \\
\hline Visited & $515(16.7)$ & $2570(83.3)$ & $3.90(2.42,6.29)$ & $3.68(2.05,6.59)^{*}$ \\
\hline \multicolumn{5}{|l|}{ Place of residence } \\
\hline Urban & 174(14.9) & $996(85.1)$ & 1.0 & 1.0 \\
\hline Rural & $432(11.4)$ & $3347(88.6)$ & $0.74(0.21,2.64)$ & $0.85(0.57,1.28)$ \\
\hline \multicolumn{5}{|l|}{ Mothers age (years) } \\
\hline $15-19$ & 23(10.3) & $201(89.7)$ & 1.0 & 1.0 \\
\hline $20-29$ & $302(11.9)$ & $2225(88.1)$ & $1.19(0.69,2.05)$ & $1.33(0.70,2.53)$ \\
\hline $30-39$ & 246(13.0) & $1652(87.0)$ & $1.30(0.75,2.27)$ & $1.71(0.86,3.44)$ \\
\hline $40-49$ & 33(11.3) & 258(88.7) & $1.12(0.57,2.18)$ & $1.74(0.78,3.85)$ \\
\hline \multicolumn{5}{|l|}{ Women's education } \\
\hline None & $345(11.3)$ & $2747(88.7)$ & 1.0 & 1.0 \\
\hline Primary & 161(11.8) & $1204(88.2)$ & $1.05(0.76,1.44)$ & $1.13(0.96,1.32)$ \\
\hline High school & $81(20.1)$ & $321(79.9)$ & $1.97(1.04,3.74)$ & $1.69(1.06,2.69)^{*}$ \\
\hline College/University & 13(15.5) & $71(84.5)$ & $1.43(0.91,2.26)$ & $1.56(0.38,6.35)$ \\
\hline \multicolumn{5}{|l|}{ Marital status } \\
\hline Currently married & $556(11.8)$ & $4150(88.2)$ & 1.0 & 1.0 \\
\hline Currently unmarried & $50(20.6)$ & 193(79.4) & $1.93(1.23,2.88)$ & $1.67(1.05,2.65)^{*}$ \\
\hline \multicolumn{5}{|l|}{ Wealth quintile } \\
\hline Poorest & $169(17.0)$ & $826(83.0)$ & 1.0 & 1.0 \\
\hline Poor & $131(13.2)$ & $863(86.8)$ & $0.74(0.49,1.11)$ & $0.80(0.58,1.11)$ \\
\hline Middle & 7397.4) & $917(92.6)$ & $0.39(0.21,0.71)$ & $0.58(0.34,0.98)^{*}$ \\
\hline Rich & $88(9.0)$ & 889(91.0) & $0.48(0.25,0.91)$ & $0.65(0.37,1.16)$ \\
\hline Richest & $145(14.6)$ & $848(85.4)$ & $0.83(0.24,2.93)$ & $0.85(0.36,2.01)$ \\
\hline \multicolumn{5}{|l|}{ Number of pregnancies } \\
\hline 1 & $145(15.1)$ & $814(84.9)$ & 1.0 & 1.0 \\
\hline $2-4$ & $271(12.2)$ & $1951(87.8)$ & $0.78(0.60,1.02)$ & $0.76(0.5,1.02)$ \\
\hline $5-6$ & 114(11.1) & $912(88.9)$ & $0.70(0.48,1.02)$ & $0.59(0.38,0.94)^{*}$ \\
\hline 7 and above & $76(10.2)$ & $666(89.8)$ & $0.64(0.41,1.00)$ & $0.53(0.29,0.93)^{*}$ \\
\hline
\end{tabular}

${ }^{*} \mathrm{p}<0.05$.

the Ethiopian Demographic Health Survey which reported (43\%) [4]. While this may be related to a general improvement of the ANC utilization after the data collection of EDHS 2011, the reasons may need to be explored further.

The majority of the women (68.3\%) started attending ANC during the second trimester which is similar to the findings of the EDHS 2011. It appears that the health benefits of early ANC attendance for the mother and fetus (newborn) are not lost by the study population. Thus efforts are required to mobilize women for ANC as early as possible.
About 25\% of the women delivered in health facilities. Although far from optimal, this appears to be higher than what was reported (10\%) in the recent EDHS [4] and a report of the Federal Ministry of Health [12]. Quite a high proportion $(87.7 \%)$ of women said that they had visited a health facility for postnatal care. Those who reported to have had PNC before 45 days were 3594 (71.8\%). The EDHS 2011 [4] reported that $91.5 \%$ of women did not receive postnatal care within 41 days after delivery and it was $1 \%$ who received post natal care within 1-2 days. Thus there is a large difference in the reported use of 
postnatal care service in this study compared to the EDHS 2011 [4]. The finding of this study is also higher than the findings of an earlier study in four major administrative regions of the country [8].

The same argument as that of increased ANC attendance can be made for increased skilled attendance at birth and postnatal care in this study. There may have been more concerted efforts to improve maternal health services utilization following the unacceptably low coverage reported by the EDHS 2011 [4].

On the other hand, reports about use of postnatal care can be influenced by the purpose and timing of visit. In some instances postnatal care coverage calculations consider visits for immunization of children, child sickness and accompanying family members, while in others this may be restricted to maternal health check up. This may affect postnatal care coverage leading to inflations [17].

\section{Limitations of the study}

This study assessed the effect of HEWs visit on maternal health utilization in two districts that represented urban and rural populations. The study areas were purposively selected. The study areas having health and demographic surveillance system may lead to the study population having better awareness and health seeking behaviors. Thus generalizations to the overall Ethiopian diverse population should be made cautiously. In addition, the cross sectional nature of the study has inherent limitations for establishing cause and effect relationships. As an observational study, it may also not have considered all potential confounding factors.

\section{Conclusions}

HEWs visit during pregnancy has generally improved utilization of maternal health services. Health facility delivery is heavily affected by other factors and possibly due to inadequate performance of HEWs to promote health facility delivery during ANC visits. Meaningful improvement in skilled attendance at birth (health facility delivery) should include other interventions on top of visits by HEWs during pregnancy. Improvement in the messages to be delivered during home visits and ANC care by HEWs should be clearly spelt out to inform the advantages of skilled attendance at birth and support preparedness for skilled attendance at birth (health facility delivery). In depth assessment of the factors affecting service utilization using qualitative methodology is recommended.

\section{Competing interests}

The authors declare that they have no competing interests.

\section{Authors' contributions}

MFA initiated the research and drafted the proposal. KA contributed to the refinement of the research question. $\mathrm{KA}, \mathrm{AM}, \mathrm{SH}, \mathrm{MA}$ and $\mathrm{SA}$ contributed to the proposal development. AM, SH, MA supervised and monitored the data collection process. SA led the process of data analysis. SA, MA, MFA, SH and AM participated in data cleaning and analysis. All authors provided in puts to the final manuscript, read and approved it.

\section{Acknowledgements}

This study was funded by the Gates Institute, Bloomberg School of Public Health JHU, for which we are very grateful. The director of the Gates Institute, Dr Amy Tsui is graciously acknowledged for her immense contribution in fostering the collaboration between the GI/SPH/JHU and the SPH/AAU and facilitating this research her technical inputs.

Our gratitude also goes to the School of Public Health, Addis Ababa University and the School's administrative and academic staff for their contribution in facilitating the study.

We are indebted to the research team members, study coordinators, all field workers and data entry clerks for their hard work in discharging their respective responsibilities.

Last, but not least we express our heartfelt gratitude to all study respondents who spared their time to participate in this study.

\section{Author details}

${ }^{1}$ Department of Reproductive Health and Health Service Management, School of Public Health, College of Health Sciences, Addis Ababa University, Addis Ababa, Ethiopia. ${ }^{2}$ Federal Ministry of Health, Addis Ababa, Ethiopia. ${ }^{3}$ Bill \& Melinda Gates Institute for Population and Reproductive Health, Population, Family and Reproductive Health Johns Hopkins Bloomberg School of Public health, Baltimore, USA.

Received: 20 October 2013 Accepted: 28 March 2014

Published: 4 April 2014

\section{References}

1. WHO, UNICEF, UNFPA WB: Trends in Maternal Mortality:1990 to 2010. Geneva: World Health Organization; 2012. Available https://www.unfpa.org/webdav/ site/global/shared/documents/publications/2012/

Trends_in_maternal_mortality_A4-1.pdf Accessed on 02/02/2014.

2. WHO, UNICEF: Count down 2015, Maternal and Child Survival: Building a Brighter Future for Women and Children, the 2012 Report. Geneva: World Health Organization; 2012. Available http://www.countdown2015mnch.org/ reports-and-articles/2012-report Accessed on 02/02/2014.

3. Lonzo R, Wang H, Foreman K, Rajaratnam J, Naghavi M, Marcus J, DwyerLindgren L, Lofgren K, Phillips D, Atkinson C, Lopez A, Murray C: Progress towards Millennium Development Goals 4 and 5 on maternal and child mortality; unupdated systematic analysis. Lancet 2011, 378:1139-1165.

4. Central Statistics Agency: Ethiopia and ICF International, Ethiopian Demographic and Health Survey. Ethiopia and Calverton, Maryland, USA: Final Report Addis Ababa; 2012. Available at measuredhs.com/pubs/pdf/ FR255/FR255.pdf. Accessed March 03,2014.

5. Federal Democratic Republic of Ethiopia: Ministry of Health. Addis Ababa, Ethiopia: The fourth Health Sector Development Plan; 2010.

6. Temiss W: Health extension program in Ethiopia: towards better access to health services for the rural poor. Federal democratic republic of Ethiopia, ministry of health. Quarterly. Health Bull 2008, 1(1):3-9.

7. Wakabi W: World report: extension workers drive Ethiopia's primary health. Lancet 2008, 372(9642):880.

8. Karim A, Betemariam W, Yalew S, Alemu H, Carnell M, Mekonnen Y: Programmatic correlates of maternal healthcare seeking behaviors in Ethiopia. Ethiop J Health Dev 2010, 24(1):92-99.

9. Karim A, Admassu K, Schellenberg J, Alemu H, Getachew N, Ameha A, Tadesse L, Betemariam W: Effect of the Ethiopia's health extension program on maternal and newborn health practices in 101 districts. PLOSE One 2013, 8:e65160.

10. Medhaniye A, Spigt M, Dinant G, Blanco R: Knowledge and performance of Ethiopian Health Extension Workers on antenatal care and delivery care. Hum Resour Health 2012, 10:44. http://www.human-resources-health.com/ content/10/1/44.

11. Federal Minsitry of Health: Health Extension Program in Ethiopia. Profile 2007. Addis Ababa.

12. Federal Democratic Republic of Ethiopia: Ministry of Health. HSDP N. Addis Ababa: Annual Performance Report EFY; 2004. 2011/2012. 
13. Gabrysch S, Campbell O: Still too far to walk: Literature review of the determinants of delivery service use. BMC Pregnancy Childbirth 2009, 9:34. doi:10.1186/1471-2393-9-34.

14. Kabakyenga JK, Östergren P-O, Turyakira E, Pettersson KO: Influence of birth preparedness, decision-making on location of birth and assistance by skilled birth attendants among women in south-western Uganda. PLOS ONE 2012, 7(4):e35747. doi:10.1371/journal.pone.0035747.

15. Mpembeni RNM, Killewo JZ, Leshabari MT, Massawe SN, Jahn A, Declare Mushi D, Mwakipa H: Use pattern of maternal health services and determinants of skilled care during delivery in Southern Tanzania: implications for achievement of MDG-5 targets. BMC Pregnancy Childbirth 2007, 7:29.

16. Hiluf M, Fantahun M: Birth Preparedness and complications readiness among women in Adigrat town, north Ethiopia. Ethiop J Health Dev 2007, 22(1):14-20

17. Abuhay M: Assessment of factors influencing utilization Of postnatal care in Gondar town north west Of Ethiopia. Addis Ababa University; 2008. MPH thesis.

doi:10.1186/1742-4755-11-28

Cite this article as: Afework et al.: Effect of an innovative community based health program on maternal health service utilization in north and south central Ethiopia: a community based cross sectional study. Reproductive Health 2014 11:28.

\section{Submit your next manuscript to BioMed Central and take full advantage of:}

- Convenient online submission

- Thorough peer review

- No space constraints or color figure charges

- Immediate publication on acceptance

- Inclusion in PubMed, CAS, Scopus and Google Scholar

- Research which is freely available for redistribution 